\title{
Cost-Effective Surgery for Cleft Lip and Palate in the Developing World: Reply to Letter to the Editor
}

\author{
D. Scott Corlew
}

Published online: 2 June 2010

(C) Société Internationale de Chirurgie 2010

\section{To the Editor,}

The letter by Thakkar et al. [1] mentions my article [2] but seemed to focus on Magee's article [3] rather than mine. The letter discusses the economics of "missions" and visiting surgeons. It needs to be pointed out that my article on the Nepal program included only cases done by Nepalese surgeons; there were no US surgeons, "missions," or other foreigners in the program. The program was supported financially and administratively by outside assistance, but all of the clinical work was done by Nepalese surgeons, with Nepalese ancillary health providers and staff. This was what allowed for optimal followup and comprehensive care for these patients as is customarily done by the surgeons in that country. As noted in the letter, this provides a different cost paradigm than that of "missions."

It appears that the information provided by Thakkar et al., in addition to the very nice analysis of data provided by Magee et al. and my efforts at economic modeling, all help in the goal of elucidating the importance not only of cleft work, but of all surgical interventions in the effort to combat loss of life and loss of productivity due to the burden of surgical disease.

\section{References}

1. Thakkar P, Shah H, Roy N (2010) Cost-effective surgery for cleft lip and palate in the developing world. World J Surg 34. doi: 10.1007/s00268-010-0553-x

2. Corlew DS (2010) Estimation of impact of surgical disease through economic modeling of cleft lip and palate care. World J Surg 34:391-396

3. Magee WP, Vander Burg R, Hatcher KW (2010) Cleft lip and palate as a cost-effective health care treatment in the developing world. World J Surg 34:420-427
D. S. Corlew $(\square)$

Interplast, 857 Maude Avenue, Mountain View, CA 94043, USA

e-mail: scorlew@interplast.org 